\title{
Complex Mosaic Ring Chromosome 11 Associated with Hemizygous Loss of 8.6 Mb of 11q24.2qter in Atypical Jacobsen Syndrome
}

\author{
Alexandra Galvão Gomes ${ }^{a}$ Carlos H. Paiva Grangeiro ${ }^{\text {a,d }} \quad$ Luiz R. Silva ${ }^{\text {e }}$ \\ Flávia G. Oliveira-Gennaro ${ }^{a}$ Ciro S. Pereira ${ }^{f}$ Tatiana M. Joaquim ${ }^{a}$ \\ Rodrigo A. Panepuccic Jeremy A. Squire ${ }^{a, b}$ Lucia Martellia, d \\ Departments of a Genetics and ${ }^{b}$ Pathology and Forensic Medicine, ${ }^{c}$ Center for Cell-Based Therapy and Regional \\ Blood Center, University of São Paulo (USP), and d Division of Clinical Genetics, Clinical Hospital of Ribeirão Preto, \\ Ribeirão Preto, ${ }^{e}$ Pediatric Clinic, Federal University of Uberlândia, Minas Gerais, and ${ }^{\mathrm{f}}$ Center of Biotechnology and \\ Cell Therapy, São Rafael Hospital, Salvador, Brazil
}

\section{Key Words}

Comparative genomic hybridization - Deletion 11q

FLI1 - Jacobsen syndrome $\cdot$ Ring chromosome .

Thrombocytopenia Paris-Trousseau type

\begin{abstract}
Jacobsen syndrome (JBS) is a contiguous gene deletion syndrome involving terminal chromosome 11q. The haploinsufficiency of multiple genes contributes to the overall clinical phenotype, which can include the variant Paris-Trousseau syndrome, a transient thrombocytopenia related to FLI1 hemizygous deletion. We investigated a boy with features of JBS using classic cytogenetic methods, FISH and high-resolution array $\mathrm{CGH}$. The proband was found to have a mosaic ring chromosome 11 resulting in a hemizygous $11 \mathrm{q}$ terminal deletion of $8.6 \mathrm{Mb}$, leading to a copy number loss of 52 genes. The patient had a hemizygous deletion in the FLI1 gene region without apparent thrombocytopenia, and he developed diabetes mellitus type I, which has not previously been described in the spectrum of disorders associated with JBS. The relationship of some of the genes within the context
\end{abstract}

\section{KARGER}

(c) 2016 S. Karger AG, Basel

E-Mail karger@karger.com

www.karger.com/msy of the phenotype caused by a partial deletion of $11 \mathrm{q}$ has provided insights concerning the developmental anomalies presented in this patient with atypical features of JBS.

(c) 2016 S. Karger AG, Basel

Jacobsen syndrome (JBS; OMIM 147791, http://omim. org/) is a contiguous gene deletion syndrome involving terminal chromosome 11q. JBS has also been reported with a familial unbalanced $11 \mathrm{q}$ translocation, a ring chromosome 11, and a pericentric $11 \mathrm{q}$ inversion associated with partial deletion. The deletion size ranges from $\sim 7$ to $20 \mathrm{Mb}$, with the proximal breakpoints usually starting within or distal to subband 11q23.3 and extending to the telomere [Mattina et al., 2009].

The spectrum of clinical symptoms is variable, and this may depend on both the size or the deleted region in 11 qter and the type of chromosome aberration involved. Typical clinical features can include pre- and postnatal growth retardation, psychomotor delay, characteristic facial dysmorphism, and thrombocytopenia or pancytopenia [Sheth et al., 2014]. A subset of JBS patients has mal- 
Table 1. List of clinical features observed in JBS present in the proband

\begin{tabular}{|c|c|}
\hline Common dysmorphic features in JBS & Proband \\
\hline \multicolumn{2}{|l|}{ Craniofacial } \\
\hline High prominent forehead & + \\
\hline Facial asymmetry & - \\
\hline Trigonocephaly & + \\
\hline Narrow forehead & + \\
\hline Flat occiput & + \\
\hline \multicolumn{2}{|l|}{ Ophthalmic } \\
\hline Telecanthus & + \\
\hline Downslanting palpebral fissures & - \\
\hline Strabismus & + \\
\hline Palpebral ptosis & + \\
\hline Bushy double eyebrows & + \\
\hline Epicanthal folds & - \\
\hline Eyelid or iris coloboma & - \\
\hline Cataract & - \\
\hline \multicolumn{2}{|l|}{ Nasal } \\
\hline Short nose & + \\
\hline Broad nasal bridge & + \\
\hline Anteverted nares & + \\
\hline Prominent columella & + \\
\hline \multicolumn{2}{|l|}{ Ear } \\
\hline Small ears & + \\
\hline Low-set ears & - \\
\hline Hypoplastic lobus & + \\
\hline \multicolumn{2}{|l|}{ Oral } \\
\hline Long and flat philtrum & + \\
\hline Carp-shaped mouth & + \\
\hline Thin upper lip & + \\
\hline Retrognathia & + \\
\hline High-arched palate & + \\
\hline Dental anomalies & + \\
\hline \multicolumn{2}{|l|}{ Neck } \\
\hline Short neck & + \\
\hline Webbed neck & - \\
\hline \multicolumn{2}{|l|}{ Hands } \\
\hline Cutaneous syndactyly & - \\
\hline Finger pads & + \\
\hline Abnormal palmar creases & + \\
\hline Hypoplastic hypotenar regions & + \\
\hline Clinodactyly of the 5 th finger & + \\
\hline Brachydactyly & - \\
\hline Camptodactyly & + \\
\hline \multicolumn{2}{|l|}{ Feet } \\
\hline Flat feet & + \\
\hline Large and long first toe & + \\
\hline Talipes equinovarus & + \\
\hline Crowded toes or syndactyly & - \\
\hline \multicolumn{2}{|l|}{ Cardiac } \\
\hline Cardiac involvement (ventricular septal defect) & + \\
\hline \multicolumn{2}{|l|}{ Hematological } \\
\hline Thrombocytopenia/pancytopenia & - \\
\hline
\end{tabular}

formations of the heart, kidney, gastrointestinal tract, genitalia, skeleton, and central nervous system. Ocular, hearing, hormonal and immunological problems such as late-onset combined immunodeficiency associated with hypogammaglobulinemia, pancytopenia, and low $\mathrm{T}$ helper cell counts may also be present [Trkova et al., 2012]. Nearly all described JBS patients are born with Paris-Trousseau syndrome, a transient neonatal thrombocytopenia associated with hemizygosity of chromosome 11q which usually includes the FLI1 gene [Hart et al., 2000].

We report an atypical case of JBS without thrombocytopenia with a complex mosaic karyotype involving a monosomy 11, a monocentric ring, and a larger dicentric ring chromosome 11 by G-banding analysis. Array CGH identified a hemizygous deletion of $8.6 \mathrm{Mb}$ which includes a loss of 52 genes from distal 11q, including the FLI1 gene. This patient developed diabetes mellitus type I which has not previously been described in the spectrum of disorders associated with JBS. The relationship of some of the genes within the deleted region of $11 \mathrm{q}$ is considered in the context of the developmental anomalies presented in this patient.

\section{Clinical Case}

The proband is a 13-year-old boy referred to the clinical genetics service with dysmorphic features (table 1), intellectual disability, and behavioral issues. He is the first-born child to a nonconsanguineous and healthy 17-year-old mother and 24-year-old father. There was no previous history of genetic diseases or diabetes in either of the parental families. The pregnancy was uncomplicated until 36 weeks' gestation, when a cesarean section had to be performed due to fetal distress and a tight nuchal cord. His birth weight was 2,560 g, his height $47.5 \mathrm{~cm}$, his OFC $33 \mathrm{~cm}$, and his APGAR score $8 / 9$. During the perinatal period, a foot deformity that was classified as metatarsus adductus was diagnosed, and a serial casting was performed. His developmental milestones were delayed.

Learning difficulties and behavioral problems, characterized by attention deficit and hyperactivity, were reported when the patient first started school. He was referred to a pediatric neurologist for evaluation and several tests were performed, including MRI which was normal. The patient was referred for major investigation and physical examination at 13 years of age, he presented with dysmorphic features that resemble JBS (fig. 1). His weight was $64.5 \mathrm{~kg}$ (90-97th percentile), his height $145 \mathrm{~cm}$ (10-25th percentile), and his OFC $52 \mathrm{~cm}$ (10th percentile). In addition to being obese, the proband has hypercholesterolemia and hypertriglyceridemia and developed diabetes mellitus type I, which is an unusual finding in JBS patients without thrombocytpenia. His hormonal and immunological systems appeared to be normal, but cardiac involvement (ventricular septal defect), in keeping with JBS, was detected. However, there were no malformations of the kidney, gastrointestinal tract, or genitalia. 

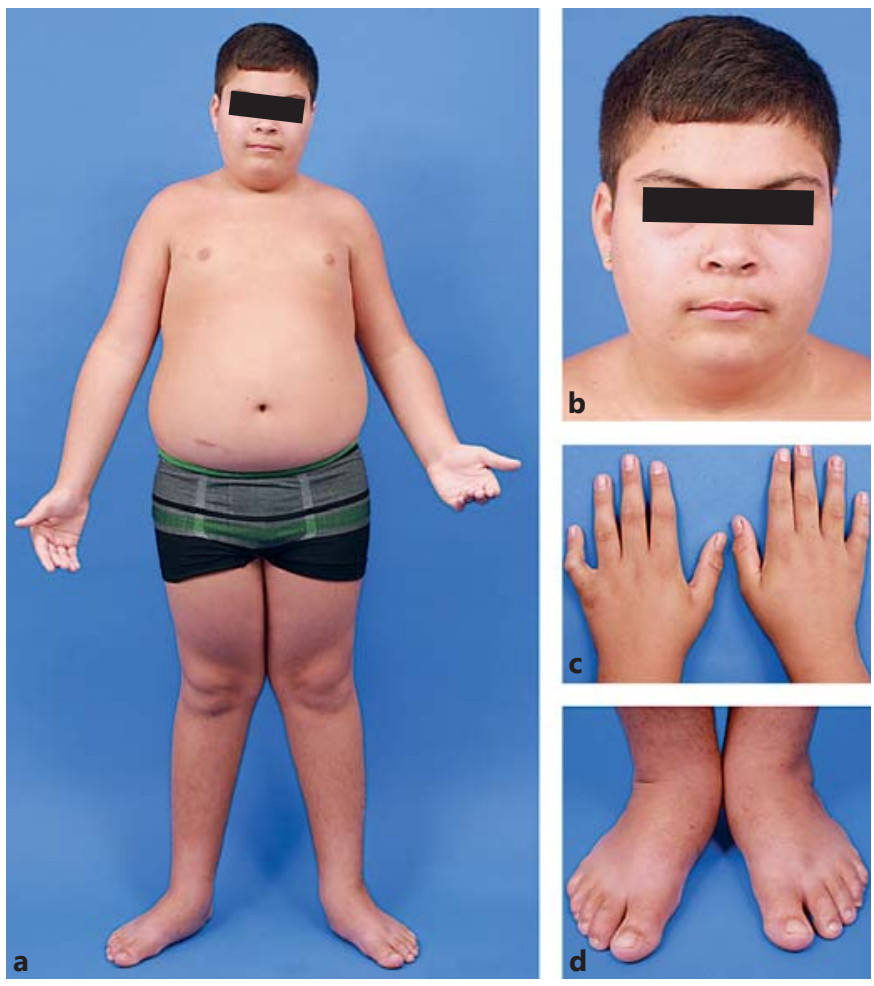

b
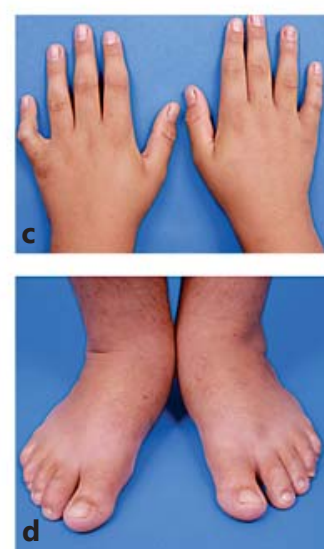

Fig. 1. Clinical features of the patient. a Frontal view of the patient b Facial features: high, prominent, narrow forehead; trigonocephaly; flat occiput; telecanthus; strabismus; palpebral ptosis; bushy double eyebrows; short nose; broad nasal bridge; anteverted nares; prominent columella; small ears; hypoplastic lobus; long, flat philtrum; carp-shaped mouth, and a thin upper lip. c Hands: clinodactyly of the 5th finger and camptodactyly. d Feet: flat feet; large, long first toe, and talipes equinovarus.

\section{Material and Methods}

A chromosome analysis of 100 metaphases was performed from 72-hour cultures of peripheral blood lymphocytes followed by conventional GTG-banding technique (400-band level resolution). Array CGH using the $2 \times 400 \mathrm{~K}$ platform (Agilent Inc., Santa Clara, Calif., USA) was performed following the protocol provided by the manufacturer. Normalization, segmentation, and identification of corresponding copy number events were done using Nexus 7.0 (BioDiscovery, Santa Clara, Calif., USA). The Fast Adaptive States Segmentation Technique (FASST2) was used to a significance threshold of $1.0 \mathrm{E}-5$ with a maximum space between adjacent probes of $1 \mathrm{~kb}$. Copy number alterations reported were based on genome build GRCh37/hg19 and were restricted to regions with 10 or more adjacent probes that differed significantly from the expected normalized values. Gain was estimated with a threshold of 0.42 ; high gains, threshold of 1.14 ; losses, -0.62 , and homozygous copy loss, -1.1 . FISH was performed with probes sureFISH (Agilent) G100333-Red 11q25 (region: 133,935,398134,140,426) and G100071-Green 11qtel (region: 134,649,534$134,945,261)$, as recommended by the manufacturer's protocol.

Ring Chromosome 11 and Atypical JBS

\section{Results}

Cytogenetic analysis by GTG-banding revealed mosaicism that comprised 3 distinct clonal cell populations with a karyotype mos 45,XY,-11[18]/46,XY,r(11)[78]/ $46, \mathrm{XY}$,dic $\mathrm{r}(11 ; 11)$ [4]. The major clone comprised $78 \%$ of the metaphase cells and was characterized by a ring chromosome 11 that appeared to be formed as a result of a small $11 \mathrm{q}$ telomeric deletion starting at band $11 \mathrm{q} 24.2$ (fig 2). The second most common clone showed monosomy of chromosome 11 (18\% of the metaphases), and the remaining $4 \%$ of metaphase cells had a large complex dicentric ring chromosome 11. Parental karyotypes were both normal. The analysis showed an $8.6-\mathrm{Mb}$ region of hemizygous loss in 11q24.2qter (chr11:126,368,150135,006,516), containing 52 genes (LOC101929427, KIRREL3, KIRREL3-AS2, MIR3167, KIRREL3-AS3, LOC101929473, LOC101929497, MIR6090, ETS1, LOC101929517, SENCR, FLI1, KCNJ1, C11orf45, KCNJ5, TP53AIP1, ARHGAP32, BARX2, LINC01395, TMEM45B, NFRKB, PRDM10, LINC00167, APLP2, ST14, ZBTB44, ADAMTS8, ADAMTS15, MIR8052, C11orf44, LOC100507431, LOC103611081, SNX19, LOC101929653, NTM, NTM-IT, OPCML, LOC646522, SPATA19, MIR4697, MIR4697HG, IGSF9B, LOC100128239, JAM3, NCAPD3, VPS26B, THYN1, ACAD8, GLB1L3, GLB1L2, $B 3 G A T 1$, and LOC283177). The array-CGH analysis showed no other structural genomic imbalances apart from the $11 \mathrm{q}$ chromosomal loss. FISH analysis using chromosome 11-specific probes showed that the ring chromosome present as the major clone had deletions in the 11q25 and 11qtel regions (fig 2).

\section{Discussion}

The literature describes 24 pre- and postnatal cases of ring abnormalities affecting chromosome 11, of which 7 cases $(29 \%)$ were thought to be associated with JBS. In 3 of them, the ring chromosome 11 was present as a mosaic, and Paris-Trousseau syndrome was associated with JBS in only 2 patients [Valente et al., 1977; Niikawa et al., 1981; Cousineau et al., 1983; Romain et al., 1983; Daniele et al., 1986; Palka et al., 1986; Fagan et al., 1988; Adewale et al., 1991; Park et al., 2007; Carella et al., 2010; Hansson et al., 2012; Iourov et al., 2012; Zhang et al., 2012; Lange et al., 2015; Peng et al., 2015]. The present study is the first analysis by array $\mathrm{CGH}$ of a mosaic ring chromosome 11 linked to JBS of a boy without evidence of neonatal thrombocytopenia. Eight patients with ring chromosome 
Fig. 2. Partial karyotypes, FISH and array analysis. a G-banding shows monosomy of chromosome 11. b Ring chromosome 11 in major clone. c Dicentric ring chromosome 11. d FISH analysis of chromosome 11 and ring chromosome (bottom arrow) shows the absence of 11q25 (red signal) and 11qtel (green signal) genomic regions (top arrow). e Copy number variation analysis by array-CGH shows an 8.6-Mb deletion in chromosome 11q24.2qter.

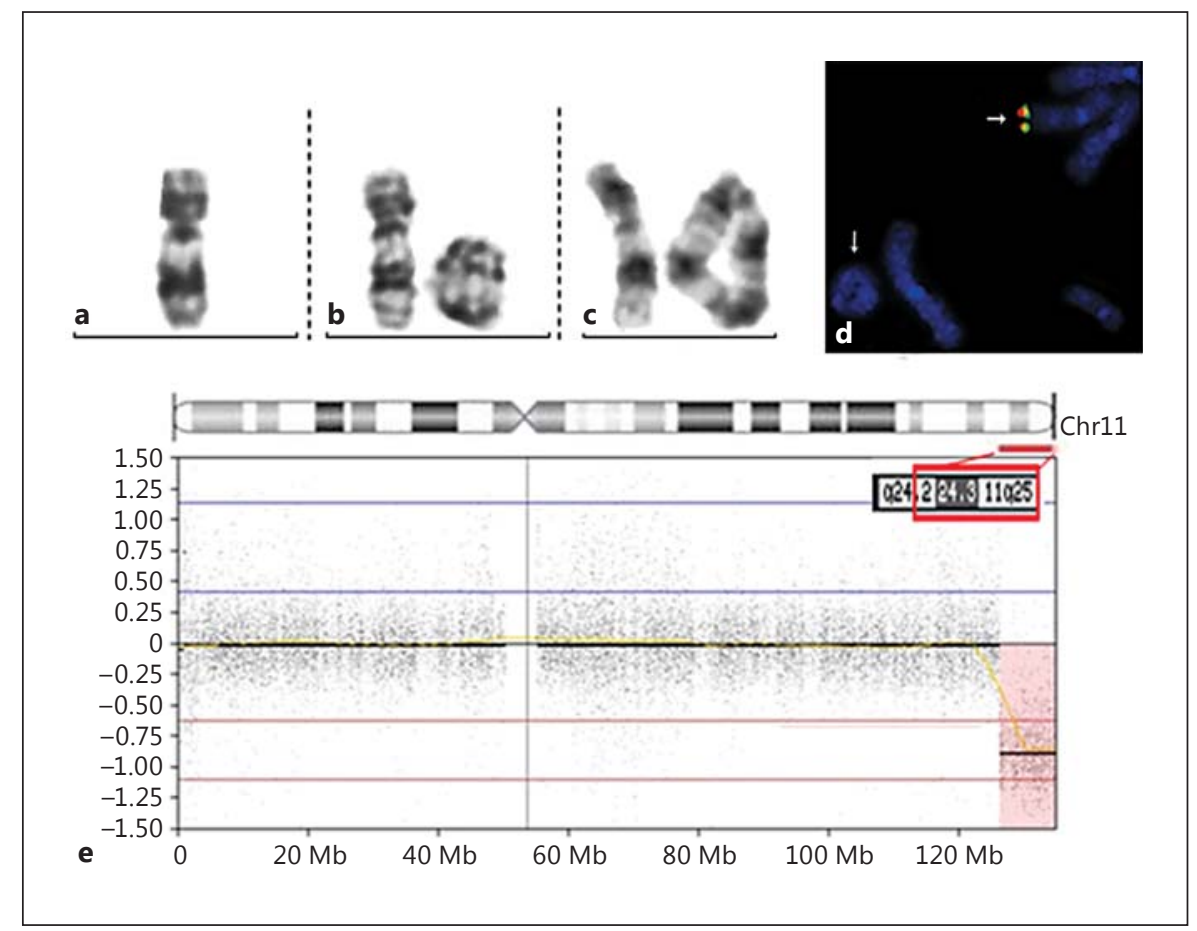

11 were studied by array CGH previously. Three of them were related to JBS, and all were female [Hansson et al., 2012; Iourov et al., 2012; Peng et al., 2015].

The deleted region of $11 \mathrm{q}$ that is associated with intellectual disability contains the genes SNX19, THYN1, OPCML, VPS26B, NCAPD3, and NTM. Deletion of the NTM gene, related to the development of the nervous system, has been associated with cognitive function. JAM3 and ETS1, suggested as candidate genes for the JBS cardiac phenotype, were also deleted.

Four genes have been related to thrombocytopenia when hemizygously deleted (FLI1, ETS1, NFRKB, and JAM3) [Trkova et al., 2012]. It is noteworthy that our patient has not developed this hematologic phenotype. Therefore, our patient is the first report of a male with JBS without thrombocytopenia, but presenting with monosomy of the genes FLI1, ETS1, NFRKB, and JAM3. At present, there are no other reports of males with FLI1 haploinsufficiency and normal platelet function and count.

Thrombocytopenia is predominant in males. Females do not appear to present with thrombocytopenia, even when the FLI1 gene is deleted [Hansson et al., 2012; Sheth et al., 2014]. Interestingly, more than $80 \%$ of the patients reported with $\mathrm{r}(11)$, and $70 \%$ with 11q deletion are female. One possible explanation for gender preference with this disorder is that the sex chromosome complement may influence the expression of chromosome 11qter, perhaps by modifying the susceptibility to develop thrombocytopenia in female patients [Peng et al., 2015].

Our patient also developed diabetes type I. However, as of now, there do not appear to be candidate genes within the deleted region to explain this phenotype. Another patient with diabetes was reported in the literature, but she presented with type II diabetes [Lange et al., 2015].

Most features of JBS may be caused by deletion of different sets of contiguous genes. The relative difference in the phenotypic expression may depend on the genetic background and gene-gene interactions. Structural rearrangements within the ring chromosome could also lead to changes in gene expression, modifying the associated clinical characteristics. The symptoms and clinical findings of $11 \mathrm{q}$ deletion are considered nonspecific, and incomplete penetrance for specific phenotypes may explain the high variability between patients [Sheth et al., 2014].

Partial monosomy 11qter in mosaic and the presence of a ring chromosome is complex for prenatal genetic counseling. Deletions in the ring chromosome, the ring instability, and epigenetic factors also must be considered in the evaluation of the genetic consequences. It is not possible to define the phenotype of the 11q partial monosomy accurately due to the heterogeneity in size and position of the deletions. In addition, variable phenotypic ef-
48

Mol Syndromol 2017;8:45-49 DOI: $10.1159 / 000452681$
Galvão Gomes et al. 
fects may arise because of modifier genes or compensatory gene expression of alleles in the normal chromosome 11. The phenotype is not only due to haploinsufficient genes; it is the result of complex epigenetic, gene-gene, and gene-environment interactions.

\section{Acknowledgments}

We thank the patient and his family for their cooperation and permission for publication. We thank Lucimar Aparecida Fernandes Laureano and Amélia Araújo for their excellent technical assistance. This study was funded by the Brazilian government (CAPES, CNPq, and FAEPA).

\section{Statement of Ethics}

All the performed procedures were in accordance with the ethical standards of the institutional and national research committee (process CONEP 13153/2006). Informed consent was obtained from the parents according to our institutional protocol.

\section{Disclosure Statement}

The authors have no conflicts of interest to declare.

\section{References}

Adewale O, Toomey KE, Punnett HH: Persistent thrombocytopenia and anemia in an infant with ring chromosome 11 syndrome. Am J Hum Genet 49 Suppl:A255 (1991).

Carella M, Spreafico F, Palumbo O, Storlazzi CT, Tabano S, et al: Constitutional ring chromosome 11 mosaicism in a Wilms tumor patient: cytogenetic, molecular and clinico-pathological studies. Am J Med Genet A 152A:17561763 (2010).

Cousineau AJ, Higgins JV, Scott-Emuakpor AB, Mody G: Brief clinical report: ring-11 chromosome: phenotype-karyotype correlation with deletions of 11q. Am J Med Genet 14: 29-35 (1983).

Daniele S, Pecorelli F, Tiepolo L, Armellini R, Liotti FS: Congenital ocular and other systemic abnormalities associated with ring-11 chromosome. Graefes Arch Clin Exp Ophthalmol 224:317-320 (1986).

Fagan K, Suthers GK, Hardacre G: Ring chromosome 11 and café-au-lait spots. Am J Med Genet 30:911-916 (1988).

Hansson KB, Gijsbers AC, Oostdijk W, Rehbock JJ, de Snoo F, et al: Molecular and clinical characterization of patients with a ring chromosome 11. Eur J Med Genet 55:708-714 (2012).
Hart A, Melet F, Grossfeld P, Chien K, Jones C, et al: $F l i-1$ is required for murine vascular and megakaryocytic development and is hemizygously deleted in patients with thrombocytopenia. Immunity 13:167-177 (2000).

Iourov IY, Vorsanova SG, Kurinnaia OS, Zelenova MA, Silvanovich AP, Yurov YB: Molecular karyotyping by array CGH in a Russian cohort of children with intellectual disability, autism, epilepsy and congenital anomalies. Mol Cytogenet 5:46 (2012).

Lange R, Von Linsingen C, Mata F, Moraes AB, Arruda M, Vieira Neto L: Endocrine abnormalities in ring chromosome 11: a case report and review of the literature. Endocrinol Diabetes Metab Case Rep 2015:150085 (2015).

Mattina T, Perrotta CS, Grossfeld P: Jacobsen syndrome. Orphanet J Rare Dis 4:9 (2009).

Niikawa N, Jinno Y, Tomiyasu T, Fukushima Y, Kudo K: Ring chromosome 11 [46,XX,r(11) (p15q25)] associated with clinical features of the 11q-syndrome. Ann Genet 24:172-175 (1981).

Palka G, Verrotti A, Peca S, Mosca L, Lombardo $\mathrm{G}$, et al: Ring chromosome 11. A case report and review of the literature. Ann Genet 29: 55-58 (1986).

Park JY, Lee MH, Lee BY, Lee YW, Ryu HM, Park SY: Prenatal diagnosis of a de novo ring chromosome 11. J Genet Med 4:80-83 (2007).
Peng Y, Ma R, Zhou Y, Xia Y, Wen J, et al: De novo ring chromosome 11 and non-reciprocal translocation of 11p15.3-pter to 21qter in a patient with congenital heart disease. Mol Cytogenet 8:88 (2015).

Romain DR, Gebbie OB, Parfitt RG, ColumbanoGreen LM, Smythe RH, et al: Two cases of ring chromosome 11. J Med Genet 20:380382 (1983).

Sheth FJ, Datar C, Andrieux J, Pandit A, Nayak D, et al: Distal deletion of chromosome 11q encompassing Jacobsen syndrome without platelet abnormality. Clin Med Insights Pediatr 8:45-49 (2014).

Trkova M, Becvarova V, Hynek M, Hnykova L, Hlavova E, et al: SNP array and phenotype correlation shows that FLI1 deletion per se is not responsible for thrombocytopenia development in Jacobsen syndrome. Am J Med Genet A 158A:2545-2550 (2012).

Valente M, Muller H, Sparkes R: Ring 11 chromosome (46,XX,r11(p15q25)). Hum Genet 36: 345-350 (1977).

Zhang H, Feng C, Tang SQ: Wilms' tumor and ring chromosome 11 in a child (in Chinese). Zhongguo Dang Dai Er Ke Za Zhi 14:993-994 (2012). 